\title{
Study on the structure-properties relationship of natural rubber/SiO 2 composites modified by a novel multi-functional rubber agent
}

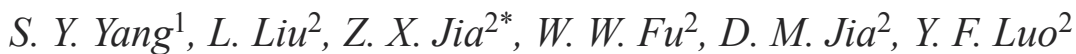 \\ ${ }^{1}$ Chemical Industrial Cleaner Production and Green Chemical R\&D Center of Guang Dong Universities, Dongguan \\ University of Technology, Dongguan, China \\ ${ }^{2}$ College of materials science and engineering, South China University of Technology, Guangzhou, China
}

Received 13 December 2014; accepted in revised form 9 February 2014

\begin{abstract}
Vulcanization property and structure-properties relationship of natural rubber (NR)/silica $\left(\mathrm{SiO}_{2}\right)$ composites modified by a novel multi-functional rubber agent, N-phenyl- $\mathrm{N}^{\prime}$-( $\gamma$-triethoxysilane)-propyl thiourea (STU), are investigated in detail. Results from the infrared spectroscopy (IR) and X-ray photoelectron spectroscopy (XPS) show that STU can graft to the surface of $\mathrm{SiO}_{2}$ under heating, resulting in a fine-dispersed structure in the rubber matrix without the connectivity of $\mathrm{SiO}_{2}$ particles as revealed by transmission electron microscopy (TEM). This modification effect reduces the block vulcanization effect of $\mathrm{SiO}_{2}$ for $\mathrm{NR} / \mathrm{SiO}_{2} / \mathrm{STU}$ compounds under vulcanization process evidently. The $400 \%$ modulus and tensile strength of $\mathrm{NR} / \mathrm{SiO}_{2} / \mathrm{STU}$ composites are much higher than that of NR/SiO2/TU composites, although the crystal index at the stretching ratio of 4 and crosslinking densities of $\mathrm{NR} / \mathrm{SiO}_{2}$ composites are almost the same at the same dosage of $\mathrm{SiO}_{2}$. Consequently, a structure-property relationship of $\mathrm{NR} / \mathrm{SiO}_{2} / \mathrm{STU}$ composites is proposed that the silane chain of STU can entangle with NR molecular chains to form an interfacial region, which is in accordance with the experimental observations quite well.
\end{abstract}

Keywords: rubber, multi-functional rubber agent, structure-property relationship, silica

\section{Introduction}

In recent years, polymer/inorganic filler composites have attracted great attention, not only in industry, but also in academia, for inorganic filler, such as silica $\left(\mathrm{SiO}_{2}\right)$, montmorillonite and halloysite nanotube can introduce great improvement in the mechanical properties of polymer/inorganic filler composites even at low dosage of filler [1]. Among these fillers, silica is believed to be one of the most important inorganic fillers applied to reinforce rubber vulcanizates because the compounding of silica offers a number of advantages on the mechanical properties of vulcanizates, such as excellent thermal stability, tensile strength, good tear and abrasion resist- ance $[2,3]$. However, because of great discrepancies in polarity between the non-polar diene polymer and polar silica, primary particles of $\mathrm{SiO}_{2}$ tend to aggregate due to the thermo-dynamical incompatibility driving force caused by hydrogen bonds among primary particles $[4,5]$. Research revealed that on a larger scale, up to macroscopic scale, the silica spatial distribution is homogeneous, with no sign of connectivity at $5 \%$ and with connectivity at $15 \%$ [6].

On the other hand, except for the well dispersion of $\mathrm{SiO}_{2}$ particles, the interfacial adhesion between polymer matrix and $\mathrm{SiO}_{2}$ particles is another essential factor for the mechanical properties of compos-

\footnotetext{
${ }^{*}$ Corresponding author, e-mail: zxjia@scut.edu.cn

(C) BME-PT
} 
ites [7], as the weak interfacial adhesion would cause catastrophic damages to the matrix under applied stress. Thus, improvements in the interfacial adhesion between the two phases, as well as good dispersion of inorganic filler particles, have been realized in the preparation of polymer-filler hybrid composites using coupling agents [8]. Nakamura et al. [9] investigated the effect of the number of siloxane units on the mechanical properties of polyisoprene/ $\mathrm{SiO}_{2}$ composites by using silanes with dialkoxy and trialkoxy structures. The reinforcement effect introduced by the silane treatment of silica was found depend strongly both on the entanglement between the silane chain and polyisoprene rubber matrix and on the crosslinking reaction between the mercapto group of silane and polyisoprene rubber in the interfacial region, which is in accordance with results from other researches [7]. However, silane coupling agents can only modify the surface of $\mathrm{SiO}_{2}$, promoting a good dispersion of $\mathrm{SiO}_{2}$ in the rubber matrix. It has been realized that, except for the fine-dispersion of filler in rubber matrix, if the silane coupling agents possess another function of rubber agents, like acceleration function, the properties of rubber composites will be significantly promoted [8].

Moreover, binary accelerator systems are being widely applied in the rubber industry and become increasingly popular based on the fact that such binary systems can effectively facilitate the vulcanization process to be carried out at a lower temperature within a short time [10-12]. Among these binary accelerator systems, thiourea (TU) and its derivatives are favorable for improvements in the vulcanization process and mechanical properties of rubber composites [13, 14]. Kurien and Kuriakose [15] synthesized a sort of TU derivative, namely amidino thiourea (ATU), and studied the vulcanization properties of NR with binary accelerator systems including tetramethylthiuram disulphide (TMTD), mercapto-benzothiazyl disulphide (MBTS), or cyclohexyl-benzthiazyl-sulphenamide (CBS). The induction time and optimum curing time of the formulations with ATU or TU were shorter than that of the control references without ATU or TU. However, all these TU derivatives only can accelerate the vulcanization process of rubber composites. Consequently, how to combine the accelerating property of $\mathrm{TU}$ and surface modification function of coupling agent together still attracted great attentions both in academy and in industry.

In this work, a multi-functional rubber agent, $\mathrm{N}$ phenyl-N'-( $\gamma$-triethoxysilane)-propyl thiourea (STU), was used to prepare $\mathrm{NR} / \mathrm{SiO}_{2}$ composites and the vulcanization property, as well as structure-properties relationship, was investigated in detail.

\section{Experimental}

\subsection{Materials}

Natural rubber ISNR-3 was used, and the other ingredients, such as zinc oxide $(\mathrm{ZnO})$, stearic acid (SA), N-cyclohexyl-2-benzothiazole sulfonamide (CBS), thiourea (TU) and sulfur (S) were commercial grades. Precipitated silica $\left(\mathrm{SiO}_{2}\right)$, with the particle diameter of about $900 \mathrm{~nm}$ and BET surface area of $144.44 \mathrm{~m}^{2} / \mathrm{g}$, was kindly supplied by Huiming Chemical Industry Co. Ltd, Wanzai County, China. The synthesis of STU was performed by mixing $\gamma$-aminopropyl triethoxysilane and phenyl isothiocyanate drop by drop in a stoichiometric level under the room temperature for 24 hours. The details in FTIR and ${ }^{1} \mathrm{H}-\mathrm{NMR}$ of STU are given as follow: FTIR, $\mathrm{cm}^{-1}$ (neat): $3275 \mathrm{br},\left(v_{\mathrm{NH}}\right) ; 3060 \mathrm{w},\left(v_{\mathrm{CH}}\right.$, arom.); $2974 \mathrm{~m}, 2927 \mathrm{~m}, 2887 \mathrm{~m}$ ( $v_{\mathrm{CH}}$, alif.); $1597 \mathrm{~m}$ (phenyl); 1536s ( $v_{\mathrm{CNC}}, \mathrm{B}-$ band); $1450 \mathrm{~m}$ ( $v_{\mathrm{C}-\mathrm{C}}$, arom.); $1165 \mathrm{~m}\left(v_{\mathrm{C}=\mathrm{S}}\right) ; 1078 \mathrm{~s}\left(v_{\mathrm{Si}-\mathrm{O}-\mathrm{Et}}\right)[16-18]$.

${ }^{1} \mathrm{H}-\mathrm{NMR}, \delta\left(\mathrm{CDCl}_{3}\right): 8.14\left(\mathrm{w}, 1 \mathrm{H}, \mathrm{N}^{\prime} \mathrm{H}\right) ; 7.37(\mathrm{~m}, 2 \mathrm{H}$, $\left.\mathrm{H}_{\mathrm{m}, \mathrm{m}^{\prime}}\right) ; 7.26\left(\mathrm{~m}, 1 \mathrm{H}, \mathrm{H}_{\mathrm{p}}\right) ; 7.18\left(\mathrm{~m}, 2 \mathrm{H}, \mathrm{H}_{\mathrm{o}, \mathrm{o}^{\prime}}\right) ; 6.25$ (w, $1 \mathrm{H}, \mathrm{NH}) ; 3.73\left(\mathrm{~s}, 6 \mathrm{H}\right.$, ethoxy $\left.\mathrm{CH}_{2}\right) ; 3.61(\mathrm{~m}, 2 \mathrm{H}$, $\left.\gamma-\mathrm{CH}_{2}\right) ; 1.68\left(\mathrm{~m}, 2 \mathrm{H}, \beta-\mathrm{CH}_{2}\right) ; 1.13$ (s, 9H, ethoxy $\left.\mathrm{CH}_{3}\right)$; and $0.55\left(\mathrm{~m}, 2 \mathrm{H}, \alpha-\mathrm{CH}_{2}\right)$. The chemistry structure of STU is displayed in Figure 1.

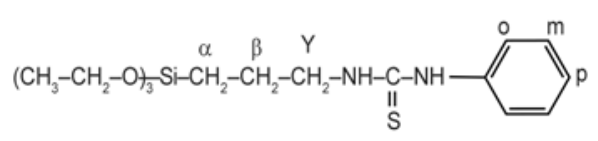

Figure 1. The chemistry structure of STU

\subsection{Preparation of $\mathrm{NR} / \mathrm{SiO}_{2}$ compounds}

The formulations of $\mathrm{NR} / \mathrm{SiO}_{2}$ compounds are summarized in Table 1 and Table 2.

NR was passed through the roller three times on an open two-roll mill $(160 \mathrm{~mm} \times 320 \mathrm{~mm})$ at room temperature with the nip gap of about $1 \mathrm{~mm}$, then other ingredients, such as $\mathrm{SiO}_{2}, \mathrm{ZnO}, \mathrm{SA}, \mathrm{TU}$ or STU, CBS and sulfur, were added to the glue stock one by one within ten minutes. After that, the compounds were stored for eight hours before the rheometer testing. 
Table 1. The formulation of $\mathrm{NR} / \mathrm{SiO}_{2} / \mathrm{STU}$ composites [phr]

\begin{tabular}{|l|c|c|c|c|c|c|c|}
\hline \multicolumn{1}{|c|}{ Sample } & NR & STU & $\mathbf{Z n O}$ & SA & CBS & S & $\mathbf{S i O}_{2}$ \\
\hline $\mathrm{STU}-\mathrm{SiO}_{2}-0$ & 100.0 & 0.92 & 5.0 & 2.0 & 2.64 & 1.5 & 0.0 \\
\hline $\mathrm{STU}-\mathrm{SiO}_{2}-10$ & 100.0 & 0.92 & 5.0 & 2.0 & 2.64 & 1.5 & 10.0 \\
\hline $\mathrm{STU}-\mathrm{SiO}_{2}-20$ & 100.0 & 0.92 & 5.0 & 2.0 & 2.64 & 1.5 & 20.0 \\
\hline $\mathrm{STU}_{-} \mathrm{SiO}_{2}-30$ & 100.0 & 0.92 & 5.0 & 2.0 & 2.64 & 1.5 & 30.0 \\
\hline $\mathrm{STU}-\mathrm{SiO}_{2}-40$ & 100.0 & 0.92 & 5.0 & 2.0 & 2.64 & 1.5 & 40.0 \\
\hline $\mathrm{STU}-\mathrm{SiO}_{2}-50$ & 100.0 & 0.92 & 5.0 & 2.0 & 2.64 & 1.5 & 50.0 \\
\hline
\end{tabular}

Table 2. The formulation of $\mathrm{NR} / \mathrm{SiO}_{2} / \mathrm{TU}$ composites [phr]

\begin{tabular}{|l|c|c|c|c|c|c|c|}
\hline \multicolumn{1}{|c|}{ Sample } & NR & TU & $\mathbf{Z n O}$ & $\mathbf{S A}$ & $\mathbf{C B S}$ & $\mathbf{S}$ & $\mathbf{S i O}_{2}$ \\
\hline $\mathrm{TU}-\mathrm{SiO}_{2}-0$ & 100.0 & 0.20 & 5.0 & 2.0 & 2.64 & 1.5 & 0.0 \\
\hline $\mathrm{TU}-\mathrm{SiO}_{2}-10$ & 100.0 & 0.20 & 5.0 & 2.0 & 2.64 & 1.5 & 10.0 \\
\hline $\mathrm{TU}-\mathrm{SiO}_{2}-20$ & 100.0 & 0.20 & 5.0 & 2.0 & 2.64 & 1.5 & 20.0 \\
\hline $\mathrm{TU}-\mathrm{SiO}_{2}-30$ & 100.0 & 0.20 & 5.0 & 2.0 & 2.64 & 1.5 & 30.0 \\
\hline $\mathrm{TU}-\mathrm{SiO}_{2}-40$ & 100.0 & 0.20 & 5.0 & 2.0 & 2.64 & 1.5 & 40.0 \\
\hline $\mathrm{TU}-\mathrm{SiO}_{2}-50$ & 100.0 & 0.20 & 5.0 & 2.0 & 2.64 & 1.5 & 50.0 \\
\hline
\end{tabular}

\subsection{Characterization}

The vulcanization research was carried out by a MDR (UR-2030SD, U-Can Limited Corporation, Taiwan, China) at $133^{\circ} \mathrm{C}$. The compounds were cured at $133^{\circ} \mathrm{C}$ according to their optimum vulcanization time. The mechanical properties, such as $400 \%$ modulus, tensile strength, and elongation at break, were measured according to ISO/DIS371994 specifications. U-CAN electron tensile testing machine was used with the crosshead speed of $500 \mathrm{~mm} / \mathrm{min}$. All mechanical testing was undertaken at $25^{\circ} \mathrm{C}$.

The possible chemical interactions between STU and $\mathrm{SiO}_{2}$ were probed by infrared spectroscopy (IR) and X-ray photoelectron spectroscopy (XPS). For preparation of samples, $\mathrm{SiO}_{2}$ and $\mathrm{STU} / \mathrm{SiO}_{2}(0.92 / 30$, phr) model compounds were placed on a vulcanizing press machine at a setting time of 15 min under $133^{\circ} \mathrm{C}$, followed by Soxhlet extraction experiment of the model compounds using boiling benzene $\left(100^{\circ} \mathrm{C}\right)$ within $24 \mathrm{~h}$, and then were dried to constant weight. The IR measurement of model compounds was recorded on a Bruker Vector 33 infrared spectroscopy in the range of $4000 \sim 400 \mathrm{~cm}^{-1}$. Also, XPS spectra of the model compounds were recorded by using an X-ray photoelectron spectrometer (Kratos Axis Ultra DLD) with an aluminum (mono) $K_{\alpha}$ source $(1486.6 \mathrm{eV})$. The aluminum $K_{\alpha}$ source was operated at $15 \mathrm{kV}$ and $10 \mathrm{~mA}$. All core level spectra were referenced to the $C_{1 \mathrm{~s}}$ neutral carbon peak at $284.7 \mathrm{eV}$.
The crosslinking density [19] test was performed on the base of swelling equilibrium measurement. The swelling equilibrium test was carried out by immersing samples in the toluene for 4 days. After that, the surface toluene was blotted off quickly with tissue paper. The specimens were immediately weighed on an analytical balance and then dried in a vacuum oven until the samples became constant weight and reweighed. The calculation was made according to the reference [20].

For the observation by transmission electron microscopy (TEM), the specimens were ultramicrotomed into thin pieces of about $100 \mathrm{~nm}$ in thickness with Leica EMUC6 under liquid nitrogen atmosphere. Then the observations were obtained using a Tecnai 12 transmission electron microscope (FEI Company, Holland) with an accelerating voltage of $100 \mathrm{kV}$.

The strain-induced crystallization (SIC) of NR/SiO composites was performed on a WAXD apparatus (Philips $\mathrm{X}^{\prime}$ Pert PRO, Holland) with Ni-filtered $\mathrm{Cu}$ $K_{\alpha}$ radiation $(\lambda=0.154 \mathrm{~nm})$ at a generator voltage of $40 \mathrm{kV}$ and generator current of $40 \mathrm{~mA}$. The $2 \theta$ scanning rang was varied from 5 to $30^{\circ}$, with a step of $0.017^{\circ}$ and a measuring time of $16.24 \mathrm{~s}$ per step. The degree of SIC $\left(X_{\mathrm{c}}\right)$ is calculated on the basis of peaks fitting during which a $2 \theta$ range from 10 to $30^{\circ}$, including crystalline and amorphous, was taken. $X_{\mathrm{c}}$ is defined as the ratio between the single integrated intensity of crystal (200 or 120 reflection was taken) $A_{\mathrm{c}}$ and the total integrated intensity of crystalline 
and amorphous peaks $A_{\mathrm{c}+\mathrm{a}}$ in the $2 \theta$ range, as expressed in the following Equation (1):

$X_{\mathrm{c}}=\frac{A_{\mathrm{c}}}{A_{\mathrm{c}+\mathrm{a}}} \times 100 \%$

\section{Results and discussions}

\subsection{Characterization of model compounds}

\subsubsection{IR spectroscopy}

Figure 2 shows the IR spectra of $\mathrm{SiO}_{2}$ and $\mathrm{STU} / \mathrm{SiO}_{2}$ model compounds. The peaks at 3441 and $1103 \mathrm{~cm}^{-1}$

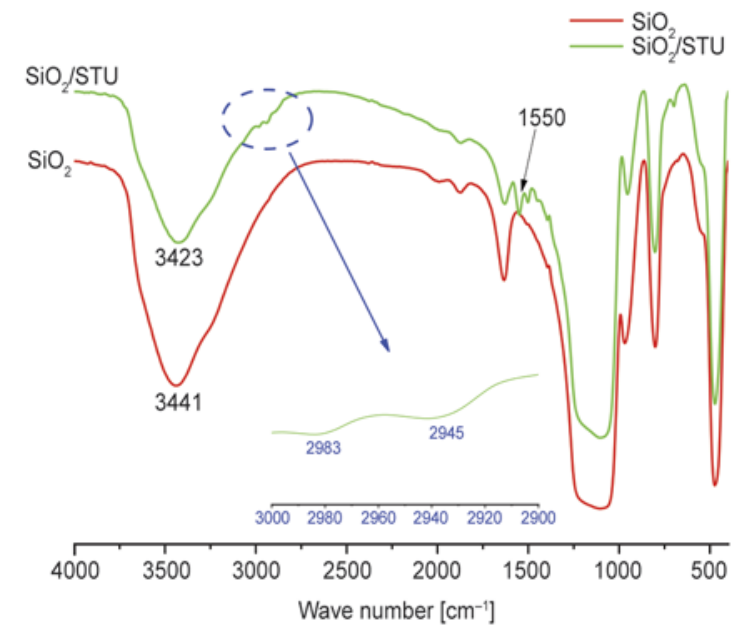

Figure 2. The IR spectra of $\mathrm{SiO}_{2}$ and $\mathrm{STU} / \mathrm{SiO}_{2}$ model compounds
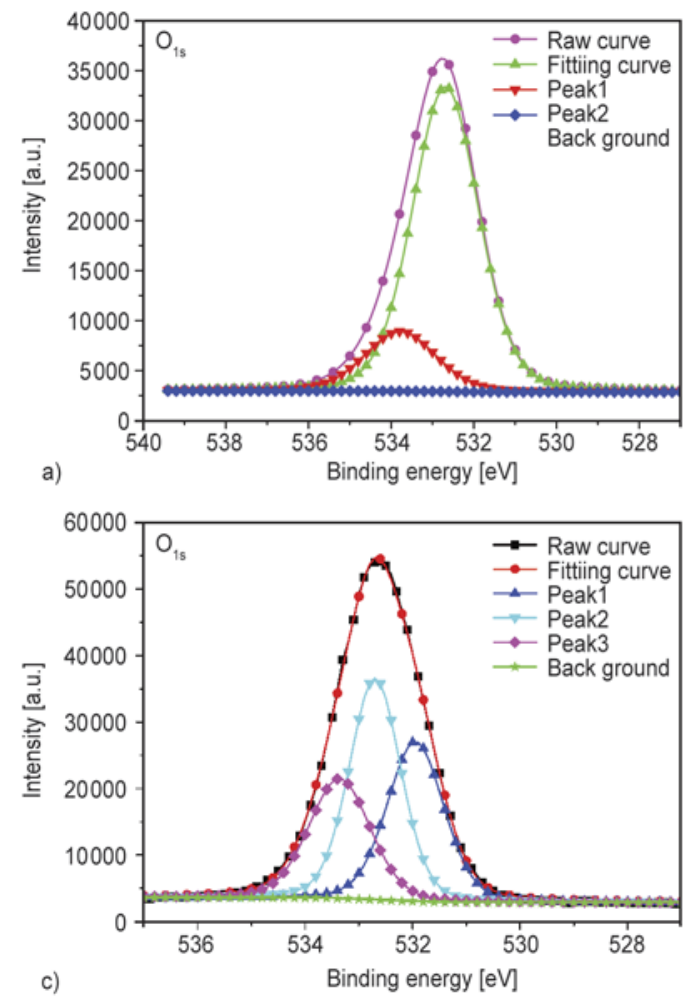

are assigned to the stretching vibrations of $-\mathrm{OH}$ groups on the surface of $\mathrm{SiO}_{2}$ and $\mathrm{Si}-\mathrm{O}$ groups, respectively. In the spectrum of $\mathrm{STU} / \mathrm{SiO}_{2}$ model compounds, the stretching vibration of $\mathrm{Si}-\mathrm{O}$ groups does not change, whereas the peak at $3423 \mathrm{~cm}^{-1}$ is associated with the stretching vibration of $-\mathrm{NH}$ groups with the bending vibration at $1550 \mathrm{~cm}^{-1}$. Two reasons may be responsible for the unconspicuous representation of $-\mathrm{OH}$ groups. First, partial hydroxyl groups have reacted with the siloxane groups of STU, leading to a decrease in the amount of $-\mathrm{OH}$ groups. Second, the silane molecules have grafted to $\mathrm{SiO}_{2}$ particles and covered on the surface of $\mathrm{SiO}_{2}$ particles, which would give rise to the shielding effect for $-\mathrm{OH}$ groups. In the dotted line ellipse domain, the peaks located at 2983 and $2945 \mathrm{~cm}^{-1}$ are ascribed to stretching vibrations of methyl and methylene. Moreover, the characteristic stretching vibrations of benzene ring $\left(1597 \mathrm{~cm}^{-1}\right)$ and $\mathrm{C}=\mathrm{S}\left(1165 \mathrm{~cm}^{-1}\right)$ have disappeared, illuminating that a pyrolysis reaction of STU occurs during heating press [21].

\subsubsection{XPS analysis}

In order to substantiate the formation of chemical bonds between $\mathrm{SiO}_{2}$ and STU, XPS survey was performed on the model compounds. The formation of
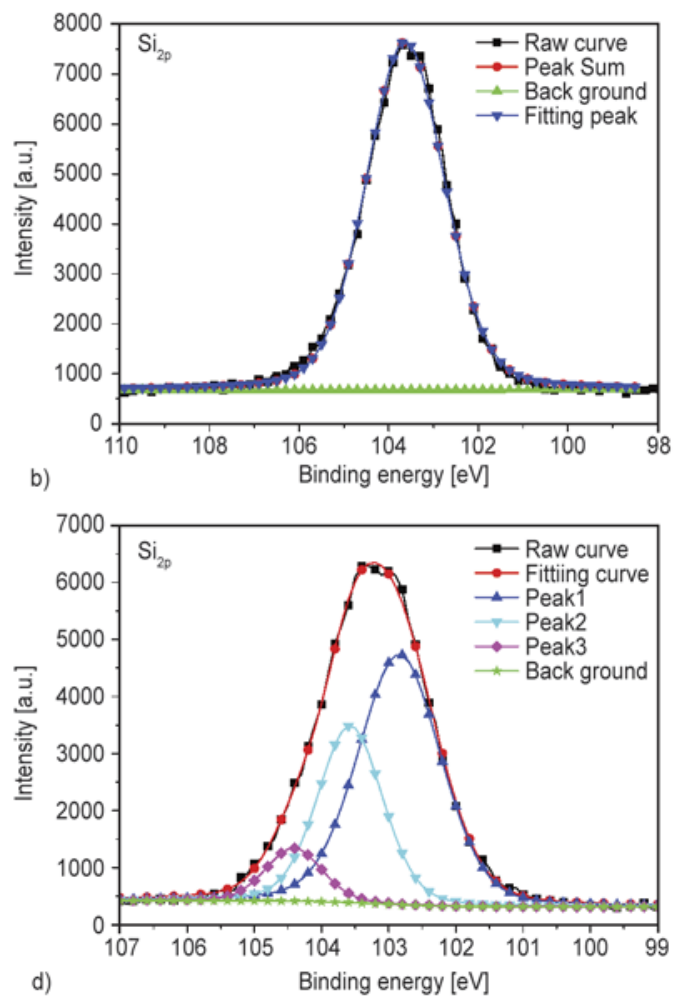

Figure 3. The XPS fitting peaks of model compounds: a) $\mathrm{O}_{1 \mathrm{~s}}$ and b) $\mathrm{Si}_{2 \mathrm{p}}$ of $\mathrm{SiO}_{2}$; c) $\mathrm{O}_{1 \mathrm{~s}}$ and d) $\mathrm{Si}_{2 \mathrm{p}}$ of $\mathrm{STU} / \mathrm{SiO}_{2}$ 
Table 3. The characteristic parameters of fitting peaks of model compounds $\mathrm{SiO}_{2}$ and $\mathrm{STU} / \mathrm{SiO}_{2}$

\begin{tabular}{|l|c|c|c|c|c|c|}
\hline \multicolumn{1}{|c|}{ Sample } & \multicolumn{3}{|c|}{$\mathbf{S i}_{\mathbf{2}}$} & \multicolumn{3}{c|}{$\mathbf{O}_{\mathbf{1 s}}$} \\
\hline $\mathrm{SiO}_{2}$ & - & 103.6 & - & - & 532.7 & 533.8 \\
\hline $\mathrm{STU} / \mathrm{SiO}_{2}$ & 102.8 & 103.6 & 104.4 & 532.0 & 532.7 & 533.4 \\
\hline
\end{tabular}

chemical bond will cause a variation in the binding energies of certain atoms related to the chemical bond. The XPS spectra of $\mathrm{SiO}_{2}$ and $\mathrm{STU} / \mathrm{SiO}_{2}$ model compounds are depicted in Figure 3 and Table 3. The characteristic signal due to silicon $\left(\mathrm{Si}_{2 \mathrm{p}}\right.$ at $103.6 \mathrm{eV}$ ) of $\mathrm{SiO}_{2}$ is detected, meanwhile, that for $\mathrm{STU} / \mathrm{SiO}_{2}$ model compounds is split into three characteristic signals, 102.8, 103.6 and $104.4 \mathrm{eV}$, respectively, indicating two new different chemical environments of silicon atom have been introduced to the surface of $\mathrm{SiO}_{2}$. Moreover, one can see that there are two different binding energies, 532.7 and $533.8 \mathrm{eV}$, of $\mathrm{O}_{1 \mathrm{~s}}$ in pure $\mathrm{SiO}_{2}$, whereas, three evident peaks are found in the $\mathrm{O}_{1 \mathrm{~s}}$ spectra of $\mathrm{STU} / \mathrm{SiO}_{2}$ model compounds, confirming the successful modification of $\mathrm{SiO}_{2}$ particles by $\mathrm{STU}$, as shows in Figure 4 . The silanol groups of STU can react with the hydroxyl groups on the surface of $\mathrm{SiO}_{2}$ with the elimination of ethanol [8] and phenyl isothiocyanate molecules under heating. The modification of $\mathrm{SiO}_{2}$ will further prohibit the agglomeration of $\mathrm{SiO}_{2}$ particles, as well as the physical adsorption of $\mathrm{SiO}_{2}$ to rubber agents.

\subsection{Vulcanization property of $\mathrm{NR} / \mathrm{SiO}_{2}$ compounds}

The vulcanization parameters of $\mathrm{NR} / \mathrm{SiO}_{2} / \mathrm{TU}$ compounds and $\mathrm{NR} / \mathrm{SiO}_{2} / \mathrm{STU}$ compounds are showed in Table 4 and Table 5, separately. In Table 4, the scorch time $\left(T_{\mathrm{s} 1}\right)$ and optimum curing time $\left(T_{\mathrm{c} 90}\right)$ increase with increasing $\mathrm{SiO}_{2}$, even at low $\mathrm{SiO}_{2}$ dosage, indicating that $\mathrm{SiO}_{2}$ particles can delay the vulcanization process. From the lowest torque $(M L), M L$ value, as well as the $M H$ value, dramatically change with the incorporation of $\mathrm{SiO}_{2}$, elucidating a bad dispersion of $\mathrm{SiO}_{2}$, that is, particles connectivity, in the NR matrix. In Table 5, the scorch time $\left(T_{\mathrm{s} 1}\right)$ and optimum curing time $\left(T_{\mathrm{c} 90}\right)$ also increase with increasing $\mathrm{SiO}_{2}$, however, compared with $\mathrm{NR} / \mathrm{SiO}_{2} / \mathrm{TU}$ compounds, one can see that a

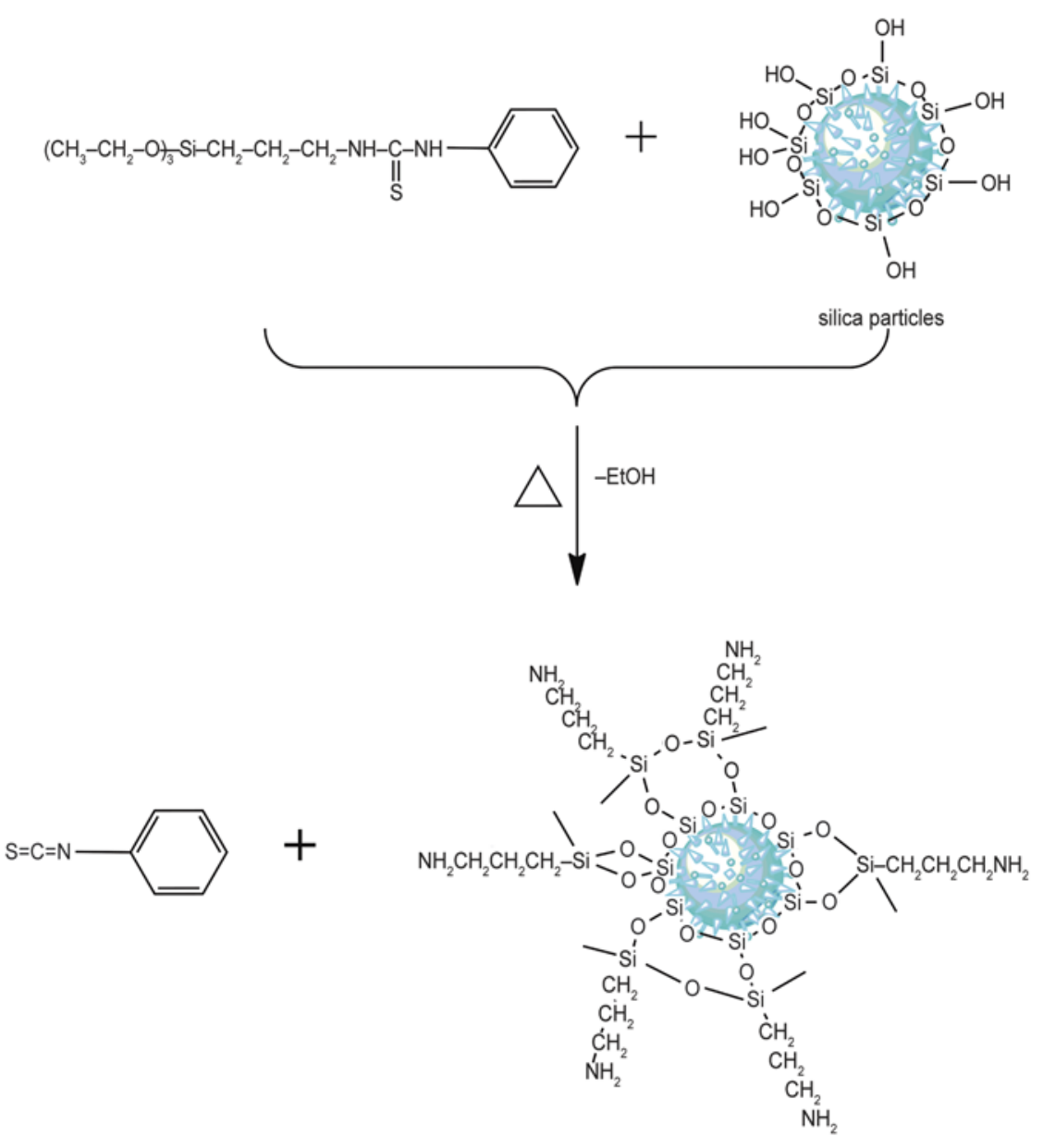

Figure 4. Schematic of STU modified silica particles 
Table 4. The curing characteristics of $\mathrm{NR} / \mathrm{SiO}_{2} / \mathrm{TU}$ compounds $\left(133^{\circ} \mathrm{C}\right)$

\begin{tabular}{|l|c|c|c|c|}
\hline \multicolumn{1}{|c|}{ Sample } & $\begin{array}{c}\mathbf{T}_{\mathbf{s 1}} \\
{[\mathbf{m i n}]}\end{array}$ & $\begin{array}{c}\mathbf{T}_{\mathbf{c 9 0}} \\
{[\mathbf{m i n}]}\end{array}$ & $\begin{array}{c}\mathbf{M L} \\
{[\mathbf{d N} \cdot \mathbf{m}]}\end{array}$ & $\begin{array}{c}\mathbf{M H} \\
{[\mathbf{d N} \cdot \mathbf{m}]}\end{array}$ \\
\hline $\mathrm{TU}-\mathrm{SiO}_{2}-0$ & 1.68 & 6.77 & 0.08 & 13.71 \\
\hline $\mathrm{TU}-\mathrm{SiO}_{2}-10$ & 5.30 & 11.10 & 0.28 & 15.15 \\
\hline $\mathrm{TU}-\mathrm{SiO}_{2}-20$ & 8.68 & 16.13 & 0.39 & 17.30 \\
\hline $\mathrm{TU}_{-}-\mathrm{SiO}_{2}-30$ & 8.90 & 17.78 & 1.16 & 22.60 \\
\hline $\mathrm{TU}-\mathrm{SiO}_{2}-40$ & 6.98 & 18.27 & 2.79 & 28.37 \\
\hline $\mathrm{TU}-\mathrm{SiO}_{2}-50$ & 9.03 & 28.27 & 4.08 & 31.07 \\
\hline
\end{tabular}

Table 5. The curing characteristics of $\mathrm{NR} / \mathrm{SiO}_{2} / \mathrm{STU}$ compounds $\left(133^{\circ} \mathrm{C}\right)$

\begin{tabular}{|l|c|c|c|c|}
\hline \multicolumn{1}{|c|}{ Sample } & $\begin{array}{c}\mathbf{T}_{\mathbf{s 1}} \\
{[\mathbf{m i n}]}\end{array}$ & $\begin{array}{c}\mathbf{T}_{\mathbf{c 9 0}} \\
{[\mathbf{m i n}]}\end{array}$ & $\begin{array}{c}\mathbf{M L} \\
{[\mathbf{d N} \cdot \mathbf{m}]}\end{array}$ & $\begin{array}{c}\mathbf{M H} \\
{[\mathbf{d N} \cdot \mathbf{m}]}\end{array}$ \\
\hline $\mathrm{STU}-\mathrm{SiO}_{2}-0$ & 3.10 & 8.15 & 0.05 & 13.20 \\
\hline $\mathrm{STU}-\mathrm{SiO}_{2}-10$ & 4.75 & 9.81 & 0.10 & 14.43 \\
\hline $\mathrm{STU}-\mathrm{SiO}_{2}-20$ & 5.63 & 10.97 & 0.10 & 14.97 \\
\hline $\mathrm{STU}-\mathrm{SiO}_{2}-30$ & 6.97 & 13.52 & 0.30 & 18.97 \\
\hline $\mathrm{STU}-\mathrm{SiO}_{2}-40$ & 8.27 & 18.85 & 1.75 & 26.27 \\
\hline $\mathrm{STU}-\mathrm{SiO}_{2}-50$ & 9.53 & 26.53 & 5.21 & 32.66 \\
\hline
\end{tabular}

more moderate increase in the $\mathrm{NR} / \mathrm{SiO}_{2} / \mathrm{STU}$ compounds, suggesting a lower physical adsorption of $\mathrm{SiO}_{2}$ particles to rubber agents. Meanwhile, when the incorporation of $\mathrm{SiO}_{2}$ is lower than $30 \mathrm{phr}$, the $M L$ or $M H$ of $\mathrm{NR} / \mathrm{SiO}_{2} / \mathrm{STU}$ compounds evolves to high value slightly, which is quite different from $\mathrm{NR} / \mathrm{SiO}_{2} / \mathrm{TU}$ compounds. This can be attributed to the modified effect of STU.

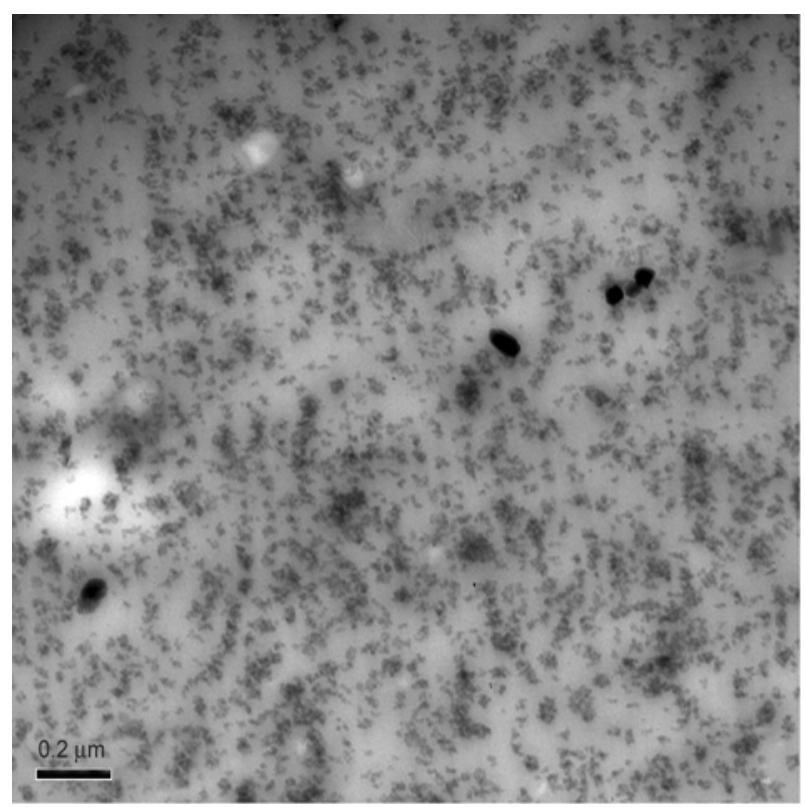

a)

\subsection{Morphology of $\mathrm{NR} / \mathrm{SiO}_{2}$ composites}

TEM technology is competent for analyzing the dispersed morphology of $\mathrm{SiO}_{2}$ particles in the rubber matrix. Figure 5 is the TEM graphs of STU$\mathrm{SiO}_{2}-30$ vulcanizate (a) and $\mathrm{TU}-\mathrm{SiO}_{2}-30$ vulcanizate (b). As is readily seen, a result can be expected that the dispersion degree of Figure 5a seems to be more homogeneous than Figure 5b, which suggests that STU facilitates $\mathrm{SiO}_{2}$ particles to disperse in NR matrix uniformly. In Figure 5a, the size of silica aggregation is reduced to a certain extent and not evident connectivity of $\mathrm{SiO}_{2}$ particles is found, that is, the $\mathrm{SiO}_{2}$ particles aggregations have been isolated by NR rubber matrix due to the modified effect of STU, as depicts in Figure 4. However, in Figure 5b, an opposite phenomenon is observed that $\mathrm{SiO}_{2}$ particles trend to agglomerate seriously and the connectivity between particles has been formed, which can be assigned to the formation of hydrogen bonds among $\mathrm{SiO}_{2}$ particles by thermodynamical driving force [7] and the huge difference in compatibility between silica particles and NR matrix.

\subsection{Strain-induced crystallization (SIC) of $\mathrm{NR} / \mathrm{SiO}_{2}$ composites}

It has been recognized long ago that the excellent tensile property of NR originates from SIC. The details of strain-induced crystallization of $\mathrm{NR} / \mathrm{SiO}_{2}$

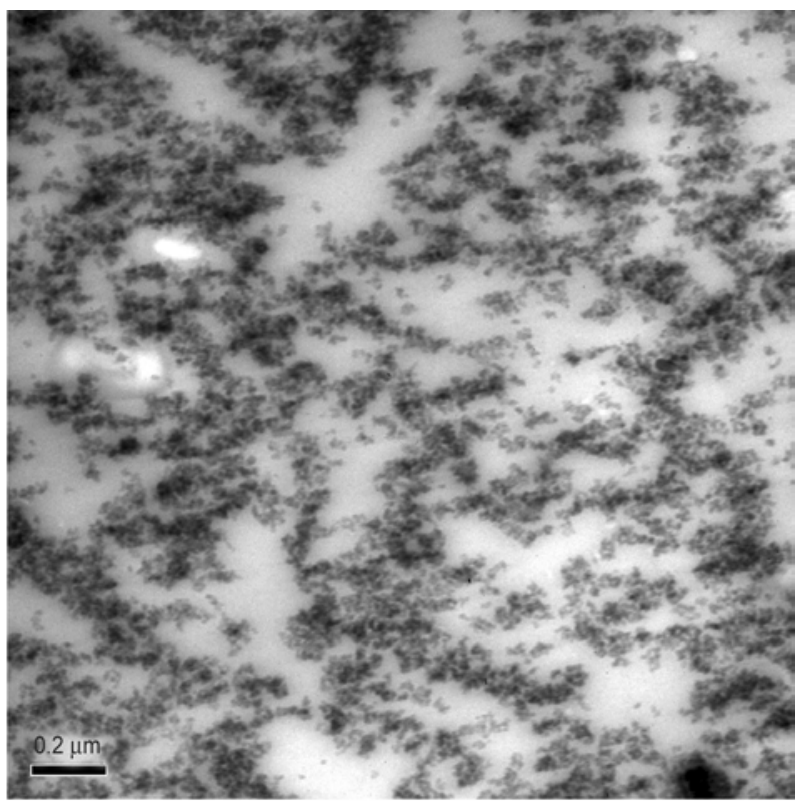

b)

Figure 5. The TEM photographs of $\mathrm{STU}-\mathrm{SiO}_{2}-30$ vulcanizate (a) and $\mathrm{TU}-\mathrm{SiO}_{2}-30$ vulcanizate (b) 

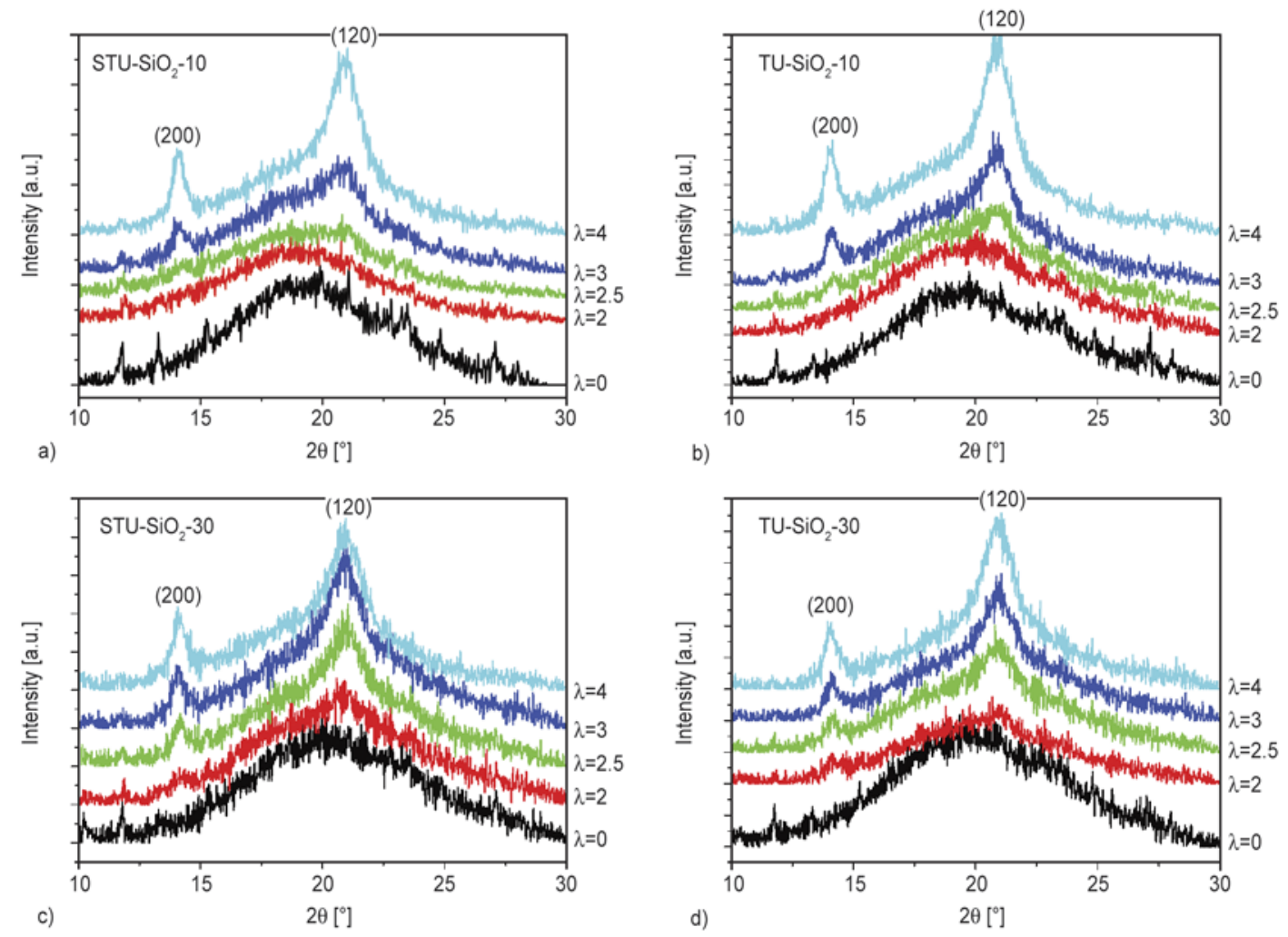

Figure 6. Equatorial diffraction profiles at selected strain values of vulcanizates as a function of strain under stretching at the $2 \theta$ angle range of $5-30^{\circ}: \mathrm{STU}_{-} \mathrm{SiO}_{2}-10$ vulcanizate (a), $\mathrm{TU}-\mathrm{SiO}_{2}-10$ vulcanizate (b), $\mathrm{STU}_{-} \mathrm{SiO}_{2}-30$ vulcanizate (c) and $\mathrm{TU}-\mathrm{SiO}_{2}-30$ vulcanizate (d)

composites experiments have been expressed in section 2.3. and the crystal index (CI) is calculated according to Equation (1). In this section, four NR/ $\mathrm{SiO}_{2}$ composites, $\mathrm{STU}-\mathrm{SiO}_{2}-10, \mathrm{STU}_{-} \mathrm{SiO}_{2}-30$, TU$\mathrm{SiO}_{2}-10$ and $\mathrm{TU}-\mathrm{SiO}_{2}-30$, is adopted to illuminate the $\mathrm{SIC}$ of $\mathrm{NR} / \mathrm{SiO}_{2}$ composites according to the dispersion state of $\mathrm{SiO}_{2}$ in the NR matrix. The dif-

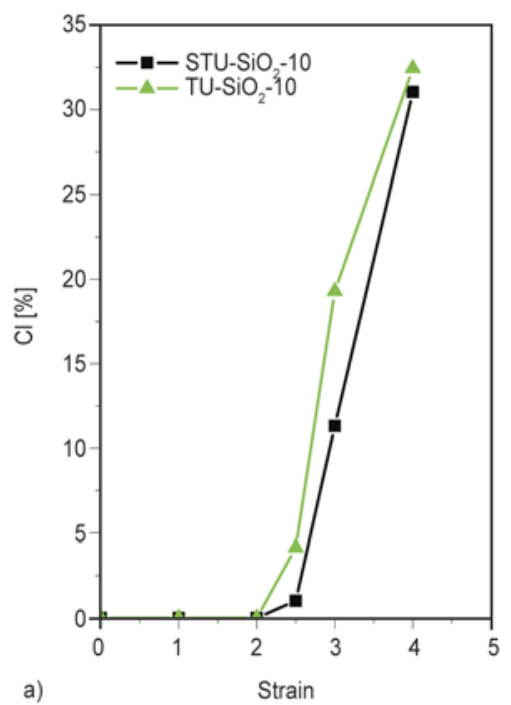

fraction profiles of $\mathrm{STU}-\mathrm{SiO}_{2}-10, \mathrm{STU}-\mathrm{SiO}_{2}-30$, TU-SiO ${ }_{2}-10$ and $\mathrm{TU}-\mathrm{SiO}_{2}-30$ under different ratio at the $2 \theta$ angle range of 5-30 are shown in Figure 6, indicating that NR is a typical strain-induced crystallization material. Figure 7 illuminates the strain dependence of $\mathrm{CI}$ of $\mathrm{NR} / \mathrm{SiO}_{2}$ composites. In Figure $7 \mathrm{a}$, when the stretching ratio is lower than 2.5 ,

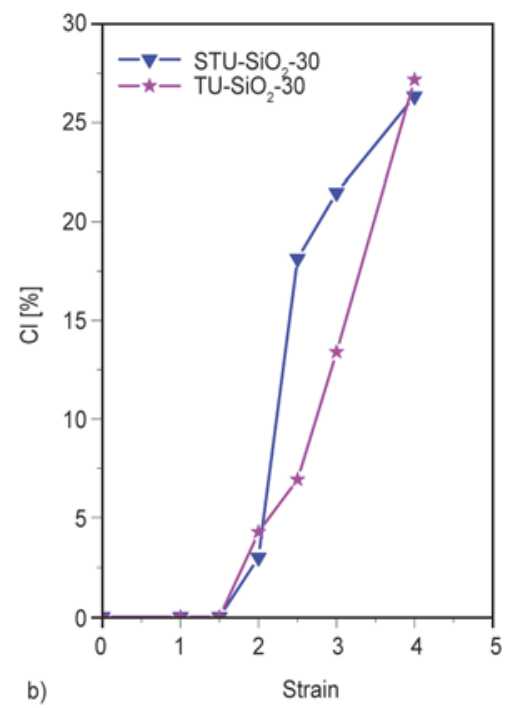

Figure 7. Variation of CI of NR with different vulcanization systems during the stretching process: filler content at $10 \mathrm{phr}$ (a) and filler content at $30 \mathrm{phr}(\mathrm{b})$ 
not crystallization can be observed in $\mathrm{STU}-\mathrm{SiO}_{2}-10$ and $\mathrm{TU}-\mathrm{SiO}_{2}-10$ composites. After that, a steep upturning appears, indicating the orientated NR molecules begin to crystallize. The SIC rate of TU-SiO ${ }_{2-}^{-}$ 10 is higher than that of $\mathrm{STU}-\mathrm{SiO}_{2}-10$, however, as the stretching ratio reaches 4 , the $\mathrm{CI}$ is not apparent difference between $\mathrm{STU}-\mathrm{SiO}_{2}-10$ and $\mathrm{TU}-\mathrm{SiO}_{2}-10$. As one can see in Figure 7b, the initial crystallization strains of STU-SiO ${ }_{2}-30$ and $\mathrm{TU}-\mathrm{SiO}_{2}-30$ are at the stretching ratio of 2 , suggesting the incorporation of $\mathrm{SiO}_{2}$ induces the NR molecules to crystallize. With respect to Figure 7a, the SIC rate of STU$\mathrm{SiO}_{2}-30$ increases faster than that of $\mathrm{TU}-\mathrm{SiO}_{2}-30$ at the stretching ratio of $2 \sim 3$, illustrating the rubber molecules in STU-SiO $2-30$ are readily to orientate. At the stretching ratio of 4 , the $\mathrm{CI}$ is almost the same between $\mathrm{STU}-\mathrm{SiO}_{2}-30$ and $\mathrm{TU}-\mathrm{SiO}_{2}-30$.

\subsection{Structure-property relationship of $\mathrm{NR} / \mathrm{SiO}_{2}$ composites}

The stress-strain behavior of $\mathrm{NR} / \mathrm{SiO}_{2}$ composites is displayed in Figure 8 and Table 6. Compared the difference between $M L$ and $M H(\triangle M=M H-M L)$ in Table 4 and 5 with the crosslinking densities in

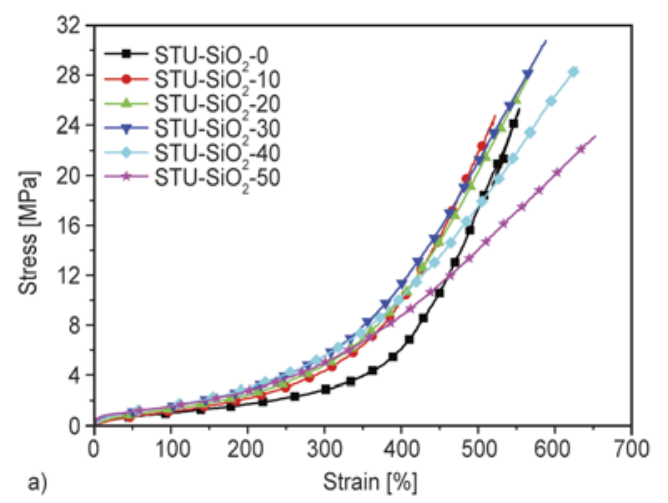

Table 6 for $\mathrm{NR} / \mathrm{SiO}_{2}$ composites, the discrepancy between $\Delta M$ and crosslinking density is mainly attributed to the hydrodynamic volume effect of filler and the hardness discrepancy between filler and rubber [22]. In the $\mathrm{NR} / \mathrm{SiO}_{2} / \mathrm{STU}$ composites, the tensile strength increases with increasing $\mathrm{SiO}_{2}$. As the addition of $\mathrm{SiO}_{2}$ reaches $30 \mathrm{phr}$, the maximum tensile strength is about $30.75 \mathrm{MPa}$, following by a decrease in the tensile strength with increasing $\mathrm{SiO}_{2}$, which is the same trend for $\mathrm{NR} / \mathrm{SiO}_{2} / \mathrm{TU}$ composites. However, the maximum tensile strength for $\mathrm{NR} / \mathrm{SiO}_{2} / \mathrm{TU}$ composites is only $25.52 \mathrm{MPa}$ at the $\mathrm{SiO}_{2}$ content of $30 \mathrm{phr}$, which is much lower than that of $\mathrm{NR} / \mathrm{SiO}_{2} / \mathrm{STU}$ composites. As is shown in Figure 7, the $\mathrm{CI}$ of $\mathrm{NR} / \mathrm{SiO}_{2}$ composites are almost the same at the stretching ratio of 4 , so in this work, for distinct understanding of the enhancement of STU, $400 \%$ modulus of $\mathrm{NR} / \mathrm{SiO}_{2}$ composites is acquired, rather than 100 and $300 \%$ modulus. $400 \%$ modulus of $\mathrm{NR} / \mathrm{SiO}_{2} / \mathrm{STU}$ composites is higher than that of $\mathrm{NR} / \mathrm{SiO}_{2} / \mathrm{TU}$ composites at the same addition of $\mathrm{SiO}_{2}$, suggesting that the reinforcing mechanism of $\mathrm{NR} / \mathrm{SiO}_{2} / \mathrm{STU}$ composites is quite different from $\mathrm{NR} / \mathrm{SiO}_{2} / \mathrm{TU}$ composites.

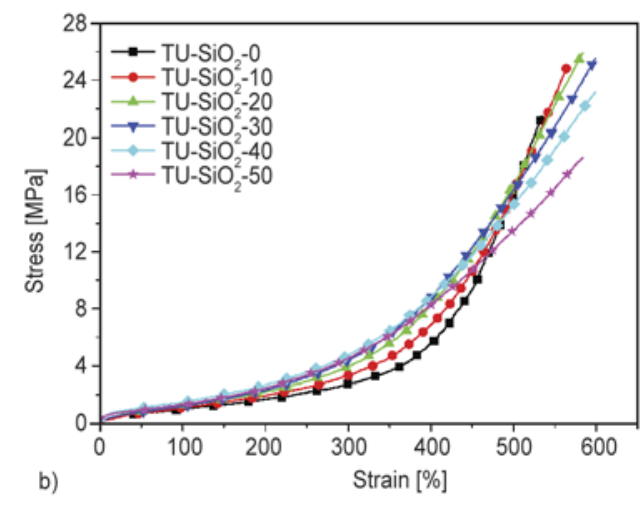

Figure 8. The stress-strain behavior of $\mathrm{NR} / \mathrm{SiO}_{2} / \mathrm{STU}$ composites (a) and $\mathrm{NR} / \mathrm{SiO}_{2} / \mathrm{TU}$ composites (b)

Table 6. The mechanical performance of $\mathrm{NR} / \mathrm{SiO}_{2}$ composites

\begin{tabular}{|c|c|c|c|c|}
\hline Sample & $\begin{array}{c}\text { 400\% Modulus } \\
\text { [MPa] }\end{array}$ & $\begin{array}{c}\text { Tensile-strength } \\
{[\mathrm{MPa}]}\end{array}$ & $\begin{array}{c}\text { Elongation at break } \\
{[\%]}\end{array}$ & $\begin{array}{c}V_{e} \\
{\left[10^{-4}\right]}\end{array}$ \\
\hline STU-SiO ${ }_{2}-0$ & 6.08 & 25.29 & 553 & 1.2290 \\
\hline STU-SiO ${ }_{2}-10$ & 9.94 & 24.74 & 522 & 1.2180 \\
\hline STU-SiO ${ }_{2}-20$ & 10.14 & 28.35 & 573 & 1.0540 \\
\hline STU-SiO ${ }_{2}-30$ & 11.26 & 30.75 & 609 & 0.9768 \\
\hline STU-SiO ${ }_{2}-40$ & 10.25 & 28.36 & 627 & 0.8505 \\
\hline STU-SiO ${ }_{2}-50$ & 8.73 & 23.11 & 646 & 0.5979 \\
\hline TU-SiO ${ }_{2}-0$ & 5.53 & 21.49 & 534 & 1.2050 \\
\hline TU-SiO ${ }_{2}-10$ & 6.84 & 24.71 & 578 & 1.1140 \\
\hline TU-SiO $2-20$ & 8.27 & 25.09 & 584 & 1.0180 \\
\hline TU-SiO ${ }_{2}-30$ & 8.79 & 25.52 & 602 & 0.8608 \\
\hline TU-SiO ${ }_{2}-40$ & 8.81 & 22.95 & 599 & 0.7152 \\
\hline TU-SiO ${ }_{2}-50$ & 8.29 & 18.07 & 592 & 0.5148 \\
\hline
\end{tabular}


It is well known that the stress-strain behavior for filler filled rubber systems is affected by the crosslinking density [23], the size of agglomerates formed by filler [24], rubber/filler interactions [7, 23] and CI (only for crystal polymer) of rubber matrix. In Table 6 and Figure 7, the crosslinking density $\left(V_{\mathrm{e}}\right)$ and total $\mathrm{CI}$ are almost the same for $\mathrm{NR} / \mathrm{SiO}_{2} / \mathrm{STU}$ composites and $\mathrm{NR} / \mathrm{SiO}_{2} / \mathrm{TU}$ composites at the same dosage of $\mathrm{SiO}_{2}$, indicating that these three factors on mechanical properties of $\mathrm{NR} / \mathrm{SiO}_{2}$ composites can be ignored. Two main reasons may be taken into consideration to represent the higher mechanical properties of $\mathrm{NR} / \mathrm{SiO}_{2} / \mathrm{STU}$ composites. First, as depicts in section 3.3. and Figure 5, the modified effect of STU gives rise to a fine-dispersion structure of $\mathrm{SiO}_{2}$ in the NR matrix, leading to the small-size effect and less defects in the interphase of NR matrix and $\mathrm{SiO}_{2}$ particles [7]. Second, the mechanical properties are found to be affected strongly by the entanglement, maybe the predominant reason, between the silane chain and NR matrix at the interfacial region, as illuminates in Figure 9. As described above, STU molecular chain, more exactly the silane chain, can graft to the surface of $\mathrm{SiO}_{2}$ particles by the reactions between the silanol groups and hydroxyl groups of $\mathrm{SiO}_{2}$ under heating. According to the theory similar molecules dissolve mutually, the silane chain can dissolve in the NR matrix, as in Figure 9a, leading to entanglement between these two molecular chains

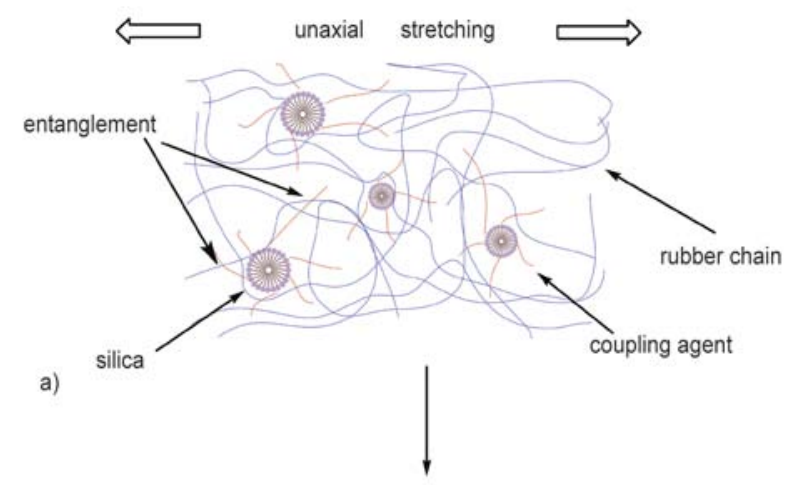

b)

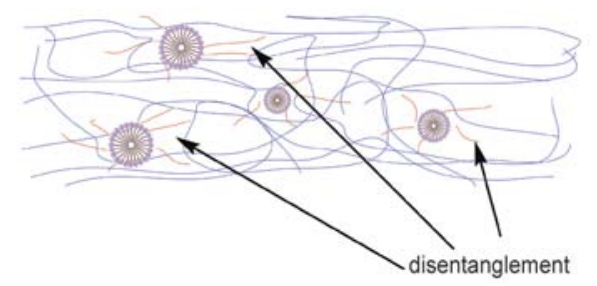

Figure 9. The reinforcement mechanism of STU modified $\mathrm{SiO}_{2}$ in the $\mathrm{NR} / \mathrm{SiO}_{2} / \mathrm{STU}$ composites: before stretching (a) and after stretching (b) at the interfacial region. When an exerted stress is applied to the matrix, the stress runs along the rubber chain, the reinforcement effect of the formed interfacial region becomes more effective to influence the modulus of $\mathrm{NR} / \mathrm{SiO}_{2} / \mathrm{STU}$ composites, leading to a much higher $400 \%$ modulus in the $\mathrm{NR} / \mathrm{SiO}_{2} /$ STU composites than that of $\mathrm{NR} / \mathrm{SiO}_{2} / \mathrm{TU}$ composites at the same addition of $\mathrm{SiO}_{2}$. As in Figure 9b, when the exerted stress continues to increase, the deformation of 'rubber depletion layer' (often a few $\mathrm{nm}$ distances away or larger $[7,25])$ surrounding $\mathrm{SiO}_{2}$ particles would develop [7]. If there are no interactions between NR matrix and $\mathrm{SiO}_{2}$ particles, decohesion would happen at the interfacial region, following by a catastrophic breakage to the composites under a low tensile strength, like the $\mathrm{NR} / \mathrm{SiO}_{2} /$ TU composites. On the other hand, when an entanglement exists in the interfacial region, like $\mathrm{NR} / \mathrm{SiO}_{2} /$ STU composites, the stress will pass from NR molecular chains to the filler effectively before disentanglement happens. At the same time, the NR main chains can slip on the $\mathrm{SiO}_{2}$ particles surface with the help of silane chains, allowing the network to relax to a more perfect regime and changing the local stress condition by means of stress homogenized distribution. These will lead to a much higher $400 \%$ modulus and tensile strength in the composites, like $\mathrm{STU}-\mathrm{SiO}_{2}-30$, before disentanglement.

\section{Conclusions}

Vulcanization property and structure-property relationship of $\mathrm{NR} / \mathrm{SiO}_{2}$ composites modified by a novel multi-functional rubber agent, STU, are explored thoroughly. From the IR and XPS spectra, STU can graft to the surface of $\mathrm{SiO}_{2}$ under heating, reducing the block vulcanization effect of $\mathrm{SiO}_{2}$ for rubber vulcanization due to the reduction in the physical adsorption of $\mathrm{SiO}_{2}$ particles to rubber agents. From the graphs of TEM, STU can facilitate a fine-dispersed structure in the rubber matrix without any connectivity of $\mathrm{SiO}_{2}$ particles, whereas, for $\mathrm{NR} / \mathrm{SiO}_{2}$ composites without modification, serious aggregation of $\mathrm{SiO}_{2}$ particles is found. Moreover, the straininduced crystallization at the stretching ratio of 4 and the crosslinking densities of $\mathrm{NR} / \mathrm{SiO}_{2}$ composites are almost the same at the same dosage of $\mathrm{SiO}_{2}$. However, the $400 \%$ modulus and tensile strength of $\mathrm{NR} / \mathrm{SiO}_{2} / \mathrm{STU}$ composites are much higher than that of $\mathrm{NR} / \mathrm{SiO}_{2} / \mathrm{TU}$ composites. Finally, a structure-property relationship of $\mathrm{NR} / \mathrm{SiO}_{2} / \mathrm{STU}$ composites is 
proposed that the silane chain of STU can entangle with NR molecular chains to form an interfacial region. When an exerted stress is applied to the matrix, the stress runs along the rubber chain, the reinforcement effect of the formed interfacial region became more effective to the mechanical properties of $\mathrm{NR} / \mathrm{SiO}_{2} / \mathrm{STU}$ composites.

\section{Acknowledgements}

The authors gratefully acknowledge the financial support from Guangdong Province Joint Funds of the National Natural Science Foundation of China (No. U1134005) and The National Natural Science Funds of China (No.51303026) and Strategic new industry core technology research project of Guangdong Province (2012A090100017).

\section{References}

[1] Xiong L., Liang H., Wang R., Chen L.: A novel route for the synthesis of poly(2-hydroxyethyl methacrylateco-methyl methacrylate) grafted titania nanoparticles via ATRP. Journal of Polymer Research, 18, 10171021 (2011).

DOI: $10.1007 / \mathrm{s} 10965-010-9502-5$

[2] Peng H., Liu L., Luo Y., Hong H., Jia D.: Synthesis and characterization of 3-benzothiazolthio-1-propyltriethoxylsilane and its reinforcement for styrenebutadiene rubber/silica composites. Journal of Applied Polymer Science, 112, 1967-1973 (2009).

DOI: 10.1002/app.29634

[3] Peng H., Liu L., Luo Y., Jia D., Fu W.: Novel blocked mercaptosilane (3-propionylthio-1-propyltrimethoxylsilane) for natural rubber/silica composite reinforcement in various curing systems. e-Polymers, 8, 11901198 (2008).

DOI: 10.1515/epoly.2008.8.1.1190

[4] Murakami K., Iio S., Ikeda Y., Ito H., Tosaka M., Kohjiya S.: Effect of silane-coupling agent on natural rubber filled with silica generated in situ. Journal of Materials Science, 38, 1447-1455 (2003).

DOI: 10.1023/A:1022908211748

[5] Yun S. H., Cho D., Kim J., Lim S., Lee G-W., Park M., Lee S-S.: Effect of silane coupling agents with different organo-functional groups on the interfacial shear strength of glass fiber/nylon 6 composites. Journal of Materials Science Letters, 22, 1591-1594 (2003). DOI: 10.1023/A:1026384408153

[6] Jouault N., Vallat P., Dalmas F., Said S., Jestin J., Boué F.: Well-dispersed fractal aggregates as filler in polymer-silica nanocomposites: Long-range effects in rheology. Macromolecules, 42, 2031-2040 (2009). DOI: $10.1021 / \mathrm{ma} 801908 \mathrm{u}$
[7] Yang S., Liu L., Jia Z., Jia D., Luo Y.: Structure and mechanical properties of rare-earth complex La-GDTC modified silica/SBR composites. Polymer, 52, 27012710 (2011).

DOI: 10.1016/j.polymer.2011.04.015

[8] Peng H., Liu L., Luo Y., Wang X., Jia D.: Effect of 3propionylthio-1-propyltrimethoxylsilane on structure, mechanical, and dynamic mechanical properties of NR/silica composites. Polymer Composites, 30, 955961 (2009).

DOI: $10.1002 / p c .20640$

[9] Nakamura Y., Honda H., Harada A., Fujii S., Nagata K.: Mechanical properties of silane-treated, silica-particle-filled polyisoprene rubber composites: Effects of the loading amount and alkoxy group numbers of a silane coupling agent containing mercapto groups. Journal of Applied Polymer Science, 113, 1507-1514 (2009).

DOI: $10.1002 / \mathrm{app} .30155$

[10] Choi S-S.: Improvement of properties of silica-filled natural rubber compounds using polychloroprene. Journal of Applied Polymer Science, 83, 2609-2616 (2002). DOI: 10.1002/app.10201

[11] González L., Rodríguez A., Del Campo A., MarcosFernández A.: Crosslink reaction of natural rubber with thiuram sulphur donors in the presence of a thiuram monosulfide. Journal of Applied Polymer Science, 85, 491-499 (2002).

DOI: $10.1002 / a p p .10438$

[12] Susamma A. P., Mini V. T. E., Kuriakose A. P.: Studies on novel binary accelerator system in sulfur vulcanization of natural rubber. Journal of Applied Polymer Science, 79, 1-8 (2001).

DOI: $10.1002 / 1097-4628(20010103) 79: 1<1:: A I D-$ APP10>3.0.CO;2-V

[13] Susamma A. P., Claramma N. M., Nair A. B., Kuriakose A. P.: New binary systems containing TMTDamidino phenyl thiourea and CBS-amidinophenyl thiourea for the vulcanization and rheological behavior of natural rubber latex. Journal of Applied Polymer Science, 115, 2310-2316 (2010).

DOI: $10.1002 / a p p .31360$

[14] Aprem A. S., Joseph K., Mathew T., Volker A., Sabu T.: Studies on accelerated sulphur vulcanization of natural rubber using 1-phenyl-2, 4-dithiobiuret/tertiary butyl benzothiazole sulphenamide. European Polymer Journal, 39, 1451-1460 (2003). DOI: $10.1016 / \mathrm{S} 0014-3057(02) 00382-8$

[15] Kurien M., Kuriakose A. P.: Studies on sulphur vulcanisation of natural rubber using amidino thiourea. Plastics, Rubber and Composites, 30, 263-269 (2001). DOI: $10.1179 / 146580101101541688$ 
[16] Cauzzi D., Costa M., Cucci N., Graiff C., Grandi F., Predieri G., Tiripicchio A., Zanoni R.: Pd(II) and Rh(I) chelate complexes of the bidentate phosphino-thiourea ligand $\mathrm{PhNHC}(\mathrm{S}) \mathrm{NHCH}_{2} \mathrm{CH}_{2} \mathrm{PPh}_{2}$ : Structural properties and activity in homogeneous and hybrid catalysis. Journal of Organometallic Chemistry, 593-594, 431444 (2000).

DOI: 10.1016/S0022-328X(99)00615-4

[17] Angelova D., Armelao L., Gross S., Kickelbick G., Seraglia R., Tondello E., Trimmel G., Venzo A.: Investigation of thiourea-silanes as viable precursors for the sol-gel synthesis of composites containing $\mathrm{Zn}-\mathrm{S}$ complexes. Applied Surface Science, 226, 144-148 (2004). DOI: $10.1016 /$ j.apsusc.2003.11.014

[18] Angelova D., Armelao L., Barison S., Fabrizio M., Gross S., Sassi A., Seraglia R., Tondello E., Trimmel G., Venzo A.: Sol-gel synthesis of $\mathrm{Zn}$-thiourea- $\mathrm{SiO}_{2}$ thin films from $(\mathrm{EtO})_{3} \mathrm{Si}\left(\mathrm{CH}_{2}\right)_{3} \mathrm{NHC}(=\mathrm{S}) \mathrm{NHPh}$ as molecular precursor. Solid State Sciences, 6, 1287-1294 (2004).

DOI: 10.1016/j.solidstatesciences.2004.06.007

[19] Flory P. J.: Statistical mechanics of swelling of network structures. The Journal of Chemical Physics, 18, 108-111 (1950).

DOI: $10.1063 / 1.1747424$
[20] Yang S., Liu L., Jia Z., Jia D., Luo Y., Liu Y.: Studies on the influence of lanthanum glutamic dithiocarbamate on the interfacial reinforncement of $\mathrm{SBR} / \mathrm{SiO}_{2}$ composites by swelling equilibrium test. Acta Polymerica Sinica, 52, 709-719 (2011).

DOI: 10.3724/SP.J.1105.2011.10184

[21] Yang S. Y., Jia Z. X., Liu L., Fu W. W., Jia D. M., Luo Y. F.: New insight into the vulcanization mechanism of novel binary accelerators for natural rubber. Chinese Journal of Polymer Science, in press (2014).

[22] Yang S., Liu L., Jia Z., Jia D., Luo Y.: Study on the curing properties of SBR/La-GDTC/SiO $\mathrm{S}_{2}$ composites. Journal of Rare Earths, 29, 444-453 (2011). DOI: 10.1016/S1002-0721(10)60477-2

[23] Yatsuyanagi F., Suzuki N., Ito M., Kaidou H.: Effects of surface chemistry of silica particles on the mechanical properties of silica filled styrene-butadiene rubber systems. Polymer Journal, 34, 332-339 (2002). DOI: $10.1295 /$ polymj.34.332

[24] Suzuki N., Yatsuyanagi F., Ito M., Kaidou H.: Effects of surface chemistry of silica particles on secondary structure and tensile properties of silica-filled rubber systems. Journal of Applied Polymer Science, 86, 16221629 (2002).

DOI: 10.1002/app.11050

[25] Starr F. W., Schrøder T. B., Glotzer S. C.: Molecular dynamics simulation of a polymer melt with a nanoscopic particle. Macromolecules, 35, 4481-4492 (2002). DOI: $10.1021 / \mathrm{ma0} 10626 \mathrm{p}$ 